Article

\title{
An Equivalent Heat Transfer Model Instead of Wind Speed Measuring for Dynamic Thermal Rating of Transmission Lines
}

\author{
Zhao Liu ${ }^{1}$, Honglei Deng ${ }^{1}{ }^{\circledR}$, Ruidong Peng ${ }^{1}$, Xiangyang Peng ${ }^{1,2}$, Rui Wang ${ }^{1,2}$, \\ Wencheng Zheng ${ }^{1}$, Pengyu Wang ${ }^{1}$, Deming Guo ${ }^{1, *}$ and Gang Liu ${ }^{1, * \mathbb{D}}$ \\ 1 School of Electric Power Engineering, South China University of Technology, Guangzhou 510640, China; \\ scliuzhao@126.com (Z.L.); denghl@scut.edu.cn (H.D.); m13077991387@163.com (R.P.); pigpxy@126.com (X.P.); \\ rickwangrui@126.com (R.W.); JMS1995scut@163.com (W.Z.); 201620111156@mail.scut.edu.cn (P.W.) \\ 2 Electric Power Research Institute of Guangdong Power Grid Co., Ltd., Guangzhou 510080, China \\ * Correspondence: 201720113678@mail.scut.edu.cn (D.G.); liugang@scut.edu.cn (G.L.); \\ Tel.: +86-156-2224-7785 (D.G.); +86-137-5179-4577 (G.L.)
}

Received: 19 August 2020; Accepted: 6 September 2020; Published: 8 September 2020

\begin{abstract}
With the increase in electricity demand, the ampacity calculation based on the dynamic thermal rating (DTR) technology is increasingly significant for assessing and improving the power transfer capacity of the existing overhead conductors. However, the DTR models now available present some inadequacies in measurement techniques related to wind speed. Therefore, it is essential to propose a new model instead of wind speed measuring in DTR technology. In this paper, the influence analysis of various weather parameters on the conductor ampacity is carried out by using the real weather data. Based on the analysis, it is confirmed that the impact of wind speed is significant, especially in the case of the low wind speed. Moreover, an equivalent heat transfer (EHT) model for DTR technology is proposed instead of wind speed measuring. For this EHT model, the calculation of conductor ampacity is realized through investigating the correlation of heat losses between the heating aluminum (Al) ball and conductor. Finally, combined with the finite element method (FEM), the EHT model proposed in this paper is verified by the Institute of Electrical and Electronic Engineers (IEEE) standard. The results indicate that the error of the EHT model is less than $6 \%$ when employing the steady thermal behavior of the Al ball to calculate the ampacity. The EHT model is useful in the real-time thermal rating of overhead conductors. It can increase the utilization of overhead conductors while also avoiding the limitation of the existing measurement techniques related to wind speed.
\end{abstract}

Keywords: dynamic thermal rating; weather parameters; overhead conductor; conductor ampacity; finite element method; heat loss

\section{Introduction}

With the rapid increase in electricity demand, it becomes a huge challenge for utilities to improve the power transfer capacity of transmission lines. To achieve this, the direct solutions are establishing new transmission lines or replacing overhead conductors which have greater power transfer capacity. However, there are some restrictions in these solutions, including the difficulties of land expropriation, long construction time and high costs [1,2]. Therefore, it is increasingly essential to maximize the utilization for power transfer capacity of the existing overhead conductors [3,4]. The economic benefits of power grid operation can also be increased [5]. In the field of power transmission, the power transfer capacity of overhead conductors can be characterized by the ampacity, which is the maximum current that the overhead conductor can carry yet within its allowable maximum temperature. The accurate 
calculation of the conductor ampacity is of great significance to quantitatively evaluate its power transfer capacity $[6,7]$.

The static thermal rating (STR) technology has been widely used to calculate the conductor ampacity. However, the results of the STR technology are calculated according to the worst weather conditions and not related to the real-time environment of operating conductor [8,9]. As a result, the conductor ampacity calculated by the STR technology is rather conservative [10]. This also means that the power transfer capacity of conductor would be under-utilized. In order to take full advantage of the implicit power transfer capacity existed in the conductor, a dynamic thermal rating (DTR) technology is proposed [11,12]. For the DTR technology, since the conductor ampacity is calculated based on the real-time weather information, the implementation of this technology needs to cooperate with the condition monitoring system.

According to the differences of monitoring data, the models of the DTR technology can be divided into two categories. The first type of DTR model, called the Weather model, calculates the conductor ampacity by directly monitoring all the weather data, including the ambient temperature, wind speed, wind direction and global solar irradiance $[13,14]$. A lot of sensors are needed to measure the weather data in Weather model [15]. Therefore, the accuracy of the ampacity results depends on the measuring precision of these sensors [16]. However, for the available wind speed sensor, due to its limited resolution, it is difficult to accurately measure the wind speed especially in the range of low wind speed [17]. This leads to a large measurement error of the wind speed sensor under the low wind speed [18]. The accuracy of the calculated conductor ampacity is also inevitably affected. Thus, other DTR models are needed to solve the inaccurate problem of wind speed measuring. To accomplish this, the second type of DTR model is presented without using the wind speed sensor.

The second type of DTR model calculates the conductor ampacity based on the operating conductor status and partial weather data $[19,20]$. In this type of DTR model, the monitored statuses of operating conductor include temperature and sag [21]. In [22], a Conductor Temperature model is proposed. The monitored conductor temperature is introduced to obtain the wind-induced heat loss during the ampacity calculation. Currently, for this model, there are two methods for conductor temperature measuring including the contact thermometry and non-contact thermometry. In the contact thermometry, the temperature sensor is installed directly on the conductor surface. This thermometry also has high measuring precision and anti-interference capability [23,24]. However, as the sensor is in direct contact with the conductor, it is difficult in terms of sensor maintenance [25]. While the non-contact thermometry such as infrared thermometry is convenient for sensor maintenance, but its measuring result is extremely susceptible to the interferences of the conductor surface state and external environment $[26,27]$.

The other model, without measuring the wind speed, is also established based on the conductor sag (i.e., Temperature-Sag model) [28,29]. Instead of measuring directly by sensors, the conductor temperature is calculated by the sag-temperature behavior [30]. However, since the existing sag monitoring technology is immature, this model has not been widely adopted [31]. As a result, considering limitations of the second type of models, there still lacks a new model instead of wind speed measuring for DTR technology.

In this paper, the influences of the weather parameters on the conductor ampacity results are analyzed by using the real weather data. An equivalent heat transfer (EHT) model which can take the place of wind speed measuring for DTR technology is proposed. During the establishment of the EHT model, the rationale and the device equipped with a heating $\mathrm{Al}$ ball are introduced, respectively. Based on the data collected by the device, the correlation of heat transfer between the Al ball and conductor is investigated. According to this correlation, the calculation of the conductor ampacity is produced. Moreover, the finite element method (FEM) is used to simulate the application of the EHT model. Combined with the simulation of the FEM, the accuracy of the EHT model is verified by comparing the ampacity results of the Institute of Electrical and Electronic Engineers (IEEE) standard. With the use of real-time condition monitoring technology, the proposed EHT model can be readily 
implemented in the field and avoid the limitations of the available measurement techniques related to wind speed.

\section{Calculation of Overhead Conductor Ampacity}

For the existing DTR model, conductor ampacity is calculated based on the data collected by the sensors. IEEE standard (IEEE Std 738-2012), CIGRE standard and Morgan formula all specify the calculation methods of conductor ampacity [32-34]. These methods are all based on the steady-state heat balance equation of conductor. Once the maximum allowable temperature of conductor is determined, the conductor ampacity can be calculated with the steady-state heat balance equation. When the conductor temperature reaches steady state, the steady-state heat balance equation of conductor is shown in (1).

$$
q_{c}+q_{r}=q_{s}+I^{2} R\left(T_{c}\right)
$$

where $q_{c}, q_{r}$ and $q_{s}$ denote the convective heat loss rate, radiative heat loss rate and solar heat gain rate of conductor per unit length, respectively, $I$ is the conductor current and $R\left(T_{c}\right)$ is the conductor resistance at the temperature of $T_{c}$. According to the IEEE standard, $R\left(T_{\mathcal{c}}\right)$ is the function related to the conductor temperature.

When the maximum allowable temperature of conductor $T_{c m a x}$ is given, the calculation formula of the conductor ampacity $I_{a m p}$ can be derived by (1), as shown in (2).

$$
I_{\text {amp }}=\sqrt{\frac{q_{c}+q_{r}-q_{s}}{R\left(T_{\text {cmax }}\right)}}
$$

\subsection{Convective Heat Loss Rate}

The convective heat loss rate of conductor per unit length $q_{c}$ is mainly related to the temperature difference between conductor and the external environment, wind speed and wind direction. According to the different heat convection modes, the calculation of $q_{c}$ is divided into two cases including natural convection and forced convection.

In the IEEE standard, natural convection is defined as the condition of zero wind speed. For the case of natural convection, the calculation of the convective heat loss rate of conductor per unit length $q_{c n}$ is as follows:

$$
q_{c n}=3.645 \rho_{f}^{0.5} D_{0}^{0.75}\left(T_{c}-T_{a}\right)^{1.25}
$$

where $\rho_{f}$ is the air density, $D_{0}$ is conductor diameter, $T_{c}$ is the temperature of conductor surface and $T_{a}$ is the ambient temperature.

For the case of forced convection, the calculation equations of convective heat loss are also different according to the magnitude of wind speed. Under the low wind speed, the forced convective heat loss rate of conductor per unit length $q_{c 1}$ can be expressed as:

$$
q_{c 1}=K_{\text {angle }}\left(1.01+1.35 R e_{c}^{0.52}\right) k_{f}\left(T_{c}-T_{a}\right)
$$

In the case of the high wind speed, the forced convective heat loss rate of conductor per unit length $q_{c 2}$ can be calculated by:

$$
q_{c 2}=K_{\text {angle }} 0.754 R e_{c}^{0.6} k_{f}\left(T_{c}-T_{a}\right)
$$

where $k_{f}$ is the thermal conductivity of air, $K_{a n g l e}$ is the wind direction factor and $R e_{c}$ is the Reynolds number of the conductor under the forced convection. $K_{\text {angle }}$ is related to the included angle $\varphi$ between 
the wind direction and the axial direction of conductor. The calculation formulas for $K_{\text {angle }}$ and $R e_{c}$ are shown in (6) and (7), respectively.

$$
\begin{gathered}
K_{\text {angle }}=1.194-\cos (\varphi)+0.194 \cos (2 \varphi)+0.368 \sin (2 \varphi) \\
\operatorname{Re}_{c}=\frac{D_{0} \rho_{f} V_{w}}{\mu_{f}}
\end{gathered}
$$

where $V_{w}$ is the wind speed and $\mu_{f}$ is the dynamic viscosity of air at the mean volume reference temperature [32,35].

In IEEE standard, the maximum value of the three calculation results from (3), (4) and (5) is selected as the final result of the convective heat loss rate [27], as shown in (8).

$$
q_{c}=\max \left(q_{c n}, q_{c 1}, q_{c 2}\right)
$$

\subsection{Radiative Heat Loss Rate}

In addition to the heat convection, the conductor also transfers energy to the surrounding environment in the form of heat radiation. The heat radiation is related to the geometric size, surface condition, temperature of conductor and ambient temperature. The calculation of radiative heat loss rate of conductor per unit length $q_{r}$ is as follows.

$$
q_{r}=\pi D_{0} \varepsilon \sigma\left[\left(T_{c}+273\right)^{4}-\left(T_{a}+273\right)^{4}\right]
$$

where $\sigma$ and $\varepsilon$ are the Steff-Boltzmann constant and emissivity of the conductor surface, respectively. The value of $\sigma$ is $5.67 \times 10^{-8} \mathrm{~W} /\left(\mathrm{m}^{2} \cdot \mathrm{K}^{4}\right)$. For the new conductor, $\varepsilon$ is set to $0.2 \sim 0.3$, while it can exceed 0.7 for the old conductor $[32,36,37]$.

\subsection{Solar Heat Gain Rate}

The heat sources of conductor also involve the solar heat gain. The solar heat gain rate of conductor is related to many factors, such as the orientation of sun and the air quality. At present, it can be calculated by two methods. The first method needs to use the geographical location (i.e., latitude data) of the conductor and time information [32], and the computational procedure of this method is complex. While for the second method, a pyranometer is employed, and the solar heat gain rate of conductor per unit length $q_{s}$ is calculated by (10) [34].

$$
q_{s}=\alpha Q_{s} D_{0}
$$

where $\alpha$ is the solar absorptivity of the conductor surface and $Q_{s}$ is the global solar irradiance. Generally, the value of $\alpha$ is equal to $\varepsilon$. $Q_{s}$ can be directly measured by the pyranometer. Compared with the first method, the second method is more accurate and its calculation procedure is simpler. However, an additional sensor is required in the second method. In this paper, the second method is chosen for the calculation of $q_{s}$.

In the aforementioned calculation of $I_{a m p}$, expressions of some parameters (such as the dynamic viscosity of air $\mu_{f}$, the air density $\rho_{f}$, and the thermal conductivity of air $k_{f}$, etc.) can be found in the IEEE standard [32].

\section{Influence of Weather Parameters on Conductor Ampacity}

According to Section 2, for a certain conductor, the calculation of $I_{\text {amp }}$ is related to the weather parameters. In this section, an aluminum conductor steel reinforced (ACSR) $240 / 30 \mathrm{~mm}^{2}$ conductor is taken as an example, and $I_{a m p}$ is calculated by using the real weather data from a weather station in Huizhou, Guangdong Province, China. The features of the ACSR $240 / 30 \mathrm{~mm}^{2}$ can be shown in Table 1 . 
These calculation results under different weather conditions are compared to investigate the influence of weather parameters on $I_{a m p}$.

Table 1. Features of the ACSR $240 / 30 \mathrm{~mm}^{2}$.

\begin{tabular}{ccc}
\hline Feature & Unit & Value \\
\hline Rated voltage & $\mathrm{kV}$ & 110 \\
Span & $\mathrm{m}$ & 300 \\
External diameter & $\mathrm{mm}$ & 21.6 \\
Total section & $\mathrm{mm}^{2}$ & 276 \\
Internal layer section (steel) & $\mathrm{mm}^{2}$ & 31.7 \\
External layer section (aluminum) & $\mathrm{mm}^{2}$ & 244 \\
Unitary mass & $\mathrm{kg} / \mathrm{km}$ & 921.5 \\
Resistance & $\Omega / \mathrm{km}$ & 0.1181 \\
\hline
\end{tabular}

\subsection{Collective Influence of Multiple Weather Parameters}

The weather parameters affecting $I_{a m p}$ include the ambient temperature $T_{a}$, global solar irradiance $Q_{s}$, wind speed $V_{w}$ and wind direction $\varphi$. Firstly, four groups are set according to varying ambient temperature alone, varying ambient temperature and global solar irradiance, varying ambient temperature and wind, and varying all of the weather parameters. Based on the real weather data from Huizhou, $I_{a m p}$ under the above four groups are calculated and compared to investigate the collective influence of weather parameters. As for the weather data under the four groups, the real-time varying weather parameters are obtained from the average value of data within one hour, while the weather parameters that need to be kept constant are the average value of all the data. Besides, in the calculation of $I_{a m p}$, the maximum allowable temperature of conductor $T_{c m a x}$ is set to $70{ }^{\circ} \mathrm{C}$, and the emissivity $\varepsilon$ and the solar absorptivity $\alpha$ of conductor surface are both set to 0.9 .

Figure 1 shows the calculation results of $I_{a m p}$ under the above four groups. The minimum, maximum, range, mean, and standard deviation of $I_{a m p}$ results in each group are also obtained by compiling the statistics of Figure 1, as shown in Table 2. It can be found from Figure 1 and Table 2 that the weather parameters have a great impact on the calculation results of $I_{a m p}$. For the two groups of varying ambient temperature alone and varying ambient temperature and global solar irradiance, the curves of calculation results show a smaller fluctuation. The corresponding range and standard deviation are also smaller. These results indicate that the ambient temperature and global solar irradiance have little influence on $I_{a m p}$, compared with other weather parameters. While after adding the influence of wind, the fluctuation of $I_{a m p}$ curves becomes significantly greater (as shown in Figure $1 c, d)$. The range and standard deviation also increase correspondingly. Therefore, the wind has a significant influence on the calculation results of $I_{a m p}$.

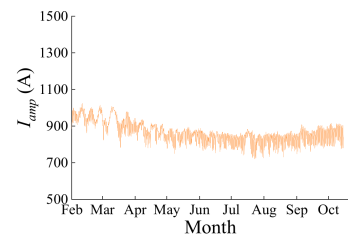

(a) varying $T_{a}$

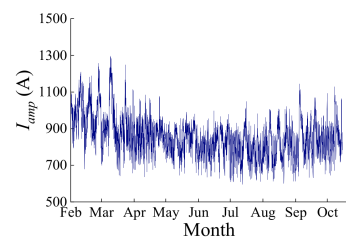

(c) varying $T_{a}, V_{w}, \varphi$

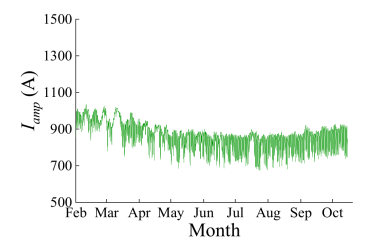

(b) varying $T_{a}, Q_{s}$

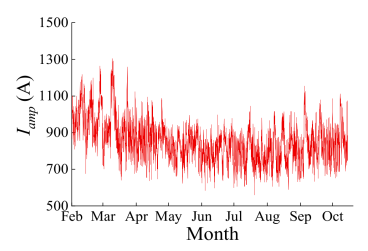

(d) varying $T_{a}, Q_{s}, V_{w}, \varphi$

Figure 1. Ampacity due to variation in weather parameter combinations. 
Table 2. Statistics of ampacity due to variation in weather parameter combinations.

\begin{tabular}{ccccc}
\hline Statistics & $T_{a}$ & $T_{a}, Q_{s}$ & $T_{a}, V_{w}, \varphi$ & $T_{a}, Q_{s}, V_{w}, \varphi$ \\
\hline Min $\left({ }^{\circ} \mathrm{C}\right)$ & 722 & 675 & 596 & 560 \\
Max $\left({ }^{\circ} \mathrm{C}\right)$ & 1024 & 1036 & 1296 & 1305 \\
Range $\left({ }^{\circ} \mathrm{C}\right)$ & 302 & 361 & 700 & 745 \\
Mean $\left({ }^{\circ} \mathrm{C}\right)$ & 866 & 865 & 855 & 855 \\
Standard deviation $\left({ }^{\circ} \mathrm{C}\right)$ & 56 & 69 & 108 & 112 \\
\hline
\end{tabular}

\subsection{Relative Importance of Single Weather Parameter}

In order to highlight the relative importance of single weather parameter, the results of $I_{a m p}$ are calculated and compared for varying ambient temperature alone, varying global solar irradiance alone, varying wind speed alone, and varying wind direction alone, respectively. The processing of weather data and the setting of conductor parameters are consistent with those in Section 3.1. The calculated results of $I_{a m p}$ are shown in Figure 2. Table 3 further demonstrates the minimum, maximum, range, mean, and standard deviation of $I_{a m p}$ results in Figure 2. By comparing the calculation results in Figure 2 and Table 3, when the global solar irradiance or wind direction varies alone, the change in $I_{a m p}$ is small. This means that the global solar irradiance and wind direction have little influence on $I_{a m p}$. While in the case of varying wind speed alone (i.e., Figure $2 \mathrm{~d}$ ), it can be found that the variability in $I_{a m p}$ substantially increases. The maximum range and standard deviation are also observed when the variation of wind speed is considered. As a result, the wind speed is an especially important factor in the calculation of $I_{a m p}$.

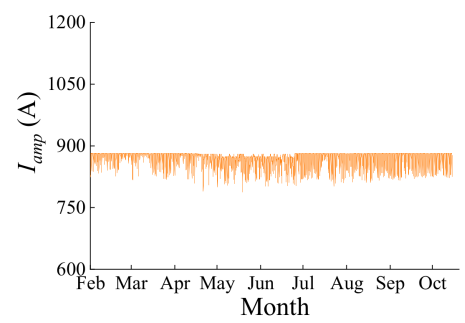

(a)varying $Q_{s}$

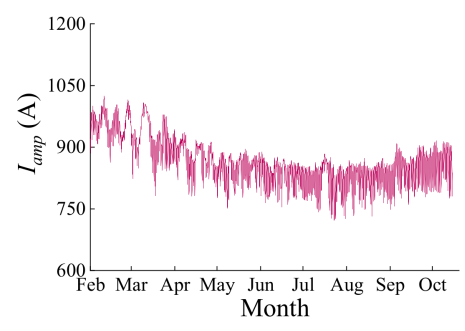

(c) varying $T_{a}$

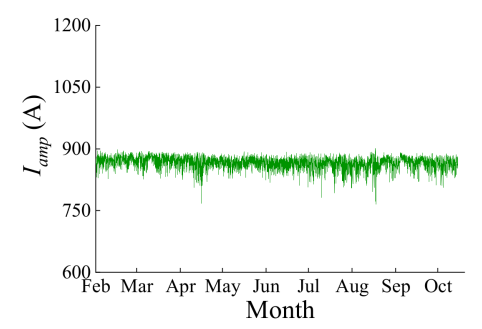

(b) varying $\varphi$

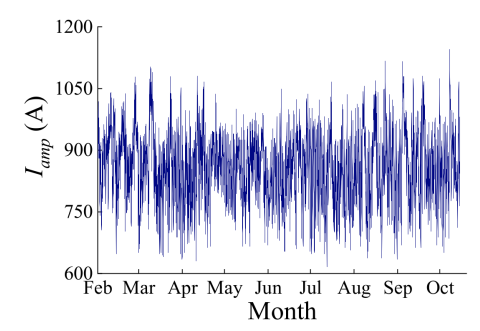

(d) varying $V_{w}$

Figure 2. Ampacity due to variation of individual weather parameters.

Table 3. Statistics of ampacity due to variation of individual weather parameters.

\begin{tabular}{ccccc}
\hline Statistics & $Q_{\boldsymbol{s}}$ & $\boldsymbol{\varphi}$ & $\boldsymbol{T}_{\boldsymbol{a}}$ & $\boldsymbol{V}_{\boldsymbol{w}}$ \\
\hline $\operatorname{Min}\left({ }^{\circ} \mathrm{C}\right)$ & 788 & 766 & 722 & 617 \\
$\operatorname{Max}\left({ }^{\circ} \mathrm{C}\right)$ & 882 & 902 & 1024 & 1146 \\
Range $\left({ }^{\circ} \mathrm{C}\right)$ & 94 & 136 & 302 & 529 \\
Mean $\left({ }^{\circ} \mathrm{C}\right)$ & 868 & 866 & 866 & 858 \\
Standard deviation $\left({ }^{\circ} \mathrm{C}\right)$ & 19 & 14 & 56 & 85 \\
\hline
\end{tabular}


To further investigate the impact of wind speed on $I_{a m p}$, assume the ambient temperature $T_{a}$ is $40{ }^{\circ} \mathrm{C}$, the global solar irradiance $Q_{s}$ is $1000 \mathrm{~W} / \mathrm{m}^{2}$, and the wind direction $\varphi$ is $90^{\circ}$, then the $I_{a m p}$ results are calculated under different wind speed $V_{w}$. The obtained results are shown in Figure 3 (i.e., black curve). Moreover, the variation rate of $I_{a m p}$ with wind speed is also introduced in Figure 3 (i.e., red curve) for the clear presentation of $I_{a m p}$ variation in different wind speed. In Figure 3, as the wind speed increases, the $I_{a m p}$ increases, while the variation rate of $I_{a m p}$ decreases. This indicates that the impact of wind speed diminishes gradually with the increase in wind speed. In the case of low wind speed, this impact is the most significant.

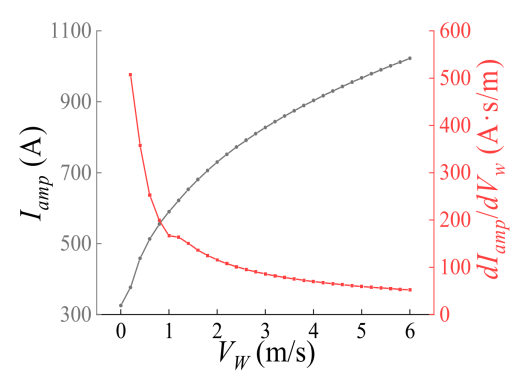

Figure 3. Ampacity due to the variation of wind speeds.

According to the above analysis, the variation of weather parameters has a great impact on the calculation results of $I_{a m p}$. Compared with other weather parameters, the impact of wind speed is the most significant. Thus, for the existing the DTR models, the larger $I_{a m p}$ calculation error is inevitably introduced when using the wind speed sensor for direct measurement. This reinforces the need to accurately obtain wind-induced heat transfer with the external environment (i.e., heat loss) in the calculation of $I_{a m p}$. To accomplish this, this paper proposes a new DTR model, called the Equivalent Heat Transfer model (EHT model), which can accurately evaluate the wind-induced heat loss without using the wind speed sensor.

\section{EHT Model of Overhead Conductor}

\subsection{Model Rationale}

Based on the correlation of heat losses between the heating $\mathrm{Al}$ ball and conductor in the same environment, an EHT model for DTR technology is proposed instead of wind speed measuring. The detailed rationale of the EHT model can be explained combined with Figure 4. In Figure 4, a device equipped with a heating $\mathrm{Al}$ ball is placed near the overhead conductor. Since the $\mathrm{Al}$ ball and conductor are in the same environment, their weather conditions including the ambient temperature, global solar irradiance, wind direction and speed are also the same. It is thought that the heat losses in the $\mathrm{Al}$ ball and conductor are related. Under this circumstance, for the Al ball of the device, its heat loss can be calculated first by its thermal behavior in a certain environment. According to the correlation of heat losses between the $\mathrm{Al}$ ball and conductor, the heat transfer between the conductor and external environment can be obtained. Then, $I_{a m p}$ in this environment is evaluated.

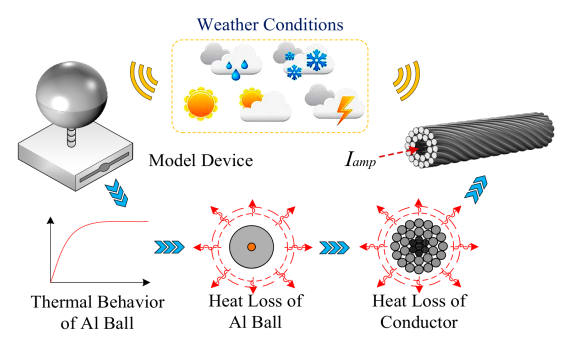

Figure 4. Rationale of the Equivalent Heat Transfer (EHT) model. 
For the EHT model proposed in this paper, $I_{\text {amp }}$ can be calculated indirectly through the thermal behavior of Al ball. The model does not need the wind speed sensor. Therefore, the inaccuracy of $I_{\text {amp }}$ calculation results arising from the measurement error of wind speed sensor can be avoided in the EHT model. Moreover, since the device equipped with the Al ball is not in contact with the conductor, difficulties of the device maintenance can be reduced effectively. The corresponding maintenance costs can also decrease.

\subsection{Model Device}

The biggest challenge for establishment of the EHT model is to obtain the correlation of heat losses between the heating $\mathrm{Al}$ ball and conductor. Figure 4 indicates that before determining this correlation, the thermal behavior of the Al ball needs to be obtained first, which comes from the device of the EHT model. Thus, the hardware facility of EHT model (i.e., model device) is introduced in this section.

The basic components of the model device include power supply, Environmental Monitoring System (EMS), Data Transmission System (DTS) and a solid Al ball, as shown in Figure 5. The power supply provides electrical energy to all modules and systems of the device. EMS can collect weather data in real time including ambient temperature, global solar irradiance and wind direction. The collected weather data are transmitted to remote servers through DTS for analysis and processing. A resistance wire and a contact temperature sensor are placed inside the solid Al ball. The purpose of the resistance wire is to heat the $\mathrm{Al}$ ball. To evenly heat the $\mathrm{Al}$ ball, the position of the resistance wire is set in the center of the $\mathrm{Al}$ ball. In addition, the power of the resistance wire will be constrained to ensure that the steady-state temperature of the $\mathrm{Al}$ ball does not exceed $50{ }^{\circ} \mathrm{C}$ under extreme environmental conditions. This can effectively avoid the damage of the device due to high temperature. The temperature sensor is used to collect the real-time temperature data of the Al ball. Based on the obtained real-time temperature data, the thermal behavior of $\mathrm{Al}$ ball can be analyzed.

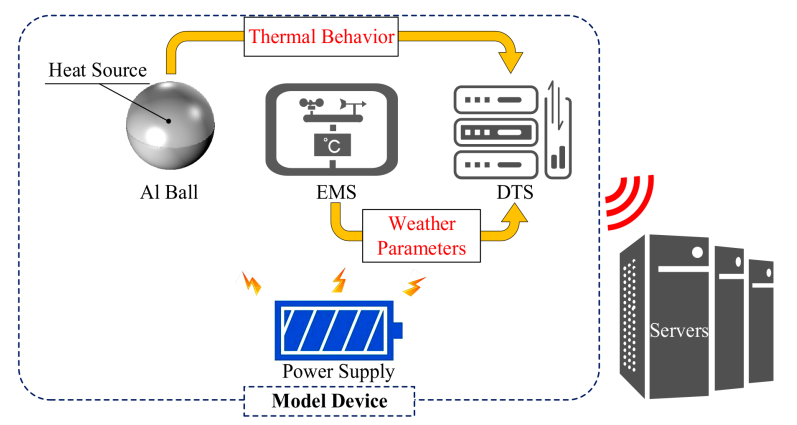

Figure 5. Frame diagram of EHT equipment.

\subsection{Calculation for Heat Loss of Al Ball}

In order to investigate the correlation of heat losses between the heating $\mathrm{Al}$ ball and conductor, the heat loss of Al ball needs to be calculated based on its thermal behavior. The thermal behavior can be expressed by the heat balance equation, as shown in (11).

$$
q_{c s}+q_{r s}+m_{s} C_{p s} \frac{d T_{s}}{d t}=q_{s s}+q_{g s}
$$

where $q_{c s}, q_{r s}, q_{s s}, q_{g s}, m_{s}, C_{p s}$ and $T_{s}$ are convective heat loss rate, radiative heat loss rate, solar heat gain rate, internal heat source power, mass, specific heat capacity and temperature of the $\mathrm{Al}$ ball, respectively, and $t$ is time. When the differential term is equal to 0 (i.e., $d T_{s} / d t=0$ ), the temperature of the $\mathrm{Al}$ ball is thought to reach the steady state.

In (11), the calculation formulas for the radiative heat loss rate and solar heat gain rate of the $\mathrm{Al}$ ball are similar to those of conductor in Section 2. The only distinction in the calculation formulas is that the geometric parameters of $\mathrm{Al}$ ball are used. For the EHT model proposed in this paper, the radiative 
heat loss rate and solar heat gain rate of the Al ball and conductor can be calculated directly by the collected weather data from the model device. The heat losses of the $\mathrm{Al}$ ball and conductor both include radiative heat loss and convective heat loss. Therefore, the correlation analysis of heat losses between the Al ball and conductor is turned into that of convective heat losses between the Al ball and conductor. In the heat transfer theory, the convective heat loss of the Al ball can be represented by the convective heat transfer coefficient $h$. According to the Newton's Law of Cooling, $h$ can be calculated by (12).

$$
h=\frac{q_{c s}}{\pi l^{2}\left(T_{s}-T_{a}\right)}
$$

where $l$ is the diameter of the $\mathrm{Al}$ ball. According to the collected real-time weather data from model device (including ambient temperature, global solar irradiance and Al ball temperature) and (11)-(12), the convective heat transfer coefficient $h$ of the $\mathrm{Al}$ ball can be calculated.

\subsection{Correlation Analysis of Convective Heat Losses between Al Ball and Conductor}

After the convective heat transfer coefficient $h$ of the Al ball is determined, the correlation of convective heat losses between the $\mathrm{Al}$ ball and conductor is established based on the characteristic numbers in the experimental correlations of heat convection. In the experimental correlations, the convective heat transfer coefficient $h$ of the $\mathrm{Al}$ ball is related to a series of characteristic numbers (including Nusselt number $N u$, Reynolds number $R e_{s}$, Prandtl number $P r$, and Grashof number Gr) $[35,38]$. Specifically, the relationship between Nusselt number $N u$ and the convective heat transfer coefficient $h$ of the $\mathrm{Al}$ ball is as follows:

$$
N u=\frac{h \cdot k_{f}}{l}
$$

Similarly, the heat convection of the Al ball can also be divided into the forced convection and natural convection. For these two cases of heat convection, there are differences in the expression of the Nusselt number $N u$. In the case of forced convection, the Nusselt number $N u$ is related to Reynolds number $R e_{S}$ and Prandtl number $P r$, and their relationship can be shown by (14) [35].

$$
N u=2+\left(0.4 \operatorname{Re}_{s}^{1 / 2}+0.06 \operatorname{Re}_{s}^{2 / 3}\right) \operatorname{Pr}^{0.4}\left(\frac{\mu_{f}}{\mu_{w}}\right)^{1 / 4}
$$

where $\mu_{w}$ denotes the dynamic viscosity of air at average surface temperature. The Reynolds number $R e_{S}$ is a function of wind speed, as shown in (15). The Prandtl number $\operatorname{Pr}$ can be calculated by (16).

$$
\begin{gathered}
R e_{s}=\frac{l \rho_{f} V_{w}}{\mu_{f}} \\
\operatorname{Pr}=\frac{\mu_{f} C_{p}}{k_{f}}
\end{gathered}
$$

where $C_{p}$ is the specific heat capacity of air, which is set at $1.005 \mathrm{~kJ} /(\mathrm{kg} \cdot \mathrm{K})$ [39].

In the case of natural convection, the Nusselt number $N u$ is related to the Grashof number $\mathrm{Gr}$ and Prandtl number $P r$, and their relationship can be expressed by (17).

$$
N u=2+\frac{0.589(G r \cdot P r)^{1 / 4}}{\left[1+(0.469 / P r)^{9 / 16}\right]^{4 / 9}}
$$

The calculation formula of the Grashof number $G r$ is as follow:

$$
G r=\frac{g \Delta t \rho_{f}^{2} l^{3}}{\left(t_{m}+273\right) \mu_{f}^{2}}
$$


where $g$ is the acceleration of gravity, $\Delta t$ is the temperature difference between the $\mathrm{Al}$ ball and environment, and $t_{m}$ is the characteristic temperature of the Al ball. The value of $t_{m}$ is the average of the $\mathrm{Al}$ ball temperature and ambient temperature.

It can be found from the above formulas that the calculation processes for characteristic numbers of the $\mathrm{Al}$ ball by using laboratory correlations are different in the case of forced convection and natural convection. However, in the EHT model, the mode of heat convection (natural convection or forced convection) cannot be determined according to the wind speed. Because the wind speed sensor is not applied. In this case, based on the determined convective heat transfer coefficient $h$ of the Al ball, the calculation result of the characteristic numbers of the $\mathrm{Al}$ ball is not unique. To solve this problem, the convection heat transfer coefficients of the Al ball under natural convection and forced convection are compared and analyzed in the following.

Under the conditions of the same ambient temperature and Al ball temperature, the forced convection heat transfer coefficients $h_{f}$ with different wind speeds and the natural convection heat transfer coefficient $h_{0}$ are firstly calculated according to (13), (14) and (17). Meanwhile, a variable $\operatorname{err}_{c}$ is introduced to compare the difference between $h_{0}$ and $h_{f}$, which is calculated by (19). The calculated $e r r_{c}$ results are shown in Figure 6.

$$
\operatorname{err}_{c}=\frac{\left|h_{f}-h_{0}\right|}{h_{0}} \times 100 \%
$$

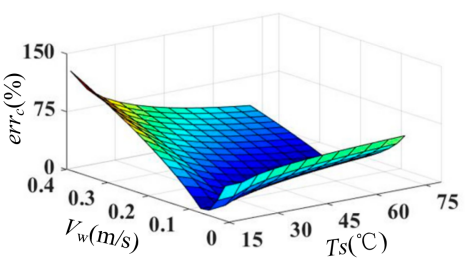

(a) $T_{a}=10^{\circ} \mathrm{C}$

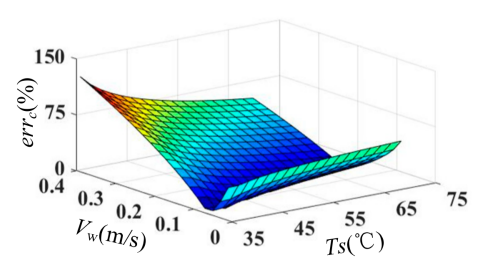

(c) $\mathrm{T}_{a}=30^{\circ} \mathrm{C}$

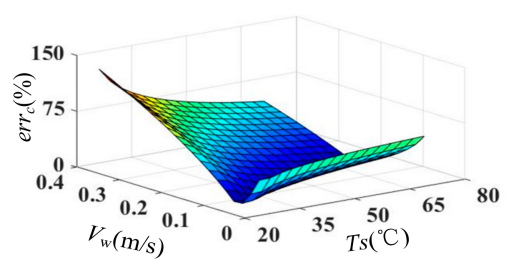

(b) $\mathrm{T}_{a}=20^{\circ} \mathrm{C}$

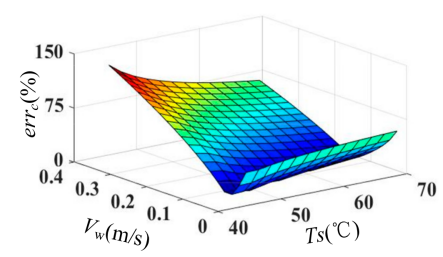

(d) $T_{a}=40^{\circ} \mathrm{C}$

Figure 6. $\operatorname{err}_{\mathrm{c}}$ results under different wind speeds and $\mathrm{Al}$ ball temperatures.

In Figure 6, the $\operatorname{err}_{c}$ results decrease first and then increase with the increase in wind speed. For any ambient temperature and $\mathrm{Al}$ ball temperature, there is a minimum value without exceeding $1.5 \%$ in the $\operatorname{err}_{C}$ results. This indicates that there is always a specific wind speed $V_{w f}$ at any ambient temperature and $\mathrm{Al}$ ball temperature, which can keep the difference between $h_{f}$ and $h_{0}$ less than $1.5 \%$. Additionally, all of the calculated specific wind speeds $V_{w f}$ in Figure 6 do not exceed $0.2 \mathrm{~m} / \mathrm{s}$. Combined with the above analysis, the natural convection of the Al ball can be equivalent to the forced convection with the wind speed of $V_{w f}$. Therefore, in the case of any modes of thermal convection, the expressions of the forced convection based on laboratory correlations (i.e., (14)-(16)) can be used to solve the characteristic numbers of Al ball.

Since the natural convection of the Al ball can be equivalent to the forced convection with a wind speed of $V_{w f}$, only the characteristic numbers involved in the expressions of the forced convection need to be considered, including the Nusselt number $N u$, Reynolds number $R e_{S}$ and Prandtl number Pr. Moreover, it can be found from (7) and (15) that the wind speed is correlated with Reynolds 
number. As a result, the correlation function for the Reynolds numbers of conductor and $\mathrm{Al}$ ball can be established through (7) and (15), as shown in (20).

$$
R e_{c}=\frac{D_{0}}{l} R e_{s}
$$

According to (20), the Reynolds number of conductor $R e_{c}$ can be calculated through the Reynolds number of the $\mathrm{Al}$ ball $R e_{s}$. Additionally, when combined with the wind direction data of the model device, the convective heat loss rate of conductor can also be determined.

\subsection{Ampacity Calculation Based on EHT Model}

For the EHT model proposed in this paper, the calculation flowchart of $I_{a m p}$ is shown in Figure 7 , and the specific implementation procedures are as follows:

(1) Calculation of convective heat transfer coefficient of Al ball. The calculation formula for convective heat transfer coefficient of $\mathrm{Al}$ ball $h$ is derived according to (11) and (12), as shown in (21). Combined with (21) and the collected weather data collected from the model device, $h$ is calculated.

$$
h=\frac{q_{s s}+q_{g s}-q_{r s}-m_{s} C_{p s} d T_{s} / d t}{\pi l^{2}\left(T_{s}-T_{a}\right)}
$$

(2) Calculation of the Reynolds number of the Al ball. After determining the convective heat transfer coefficient of the Al ball, the Reynolds number of the $\mathrm{Al}$ ball $R e_{s}$ is obtained according to (13)-(14).

(3) Calculation of convective heat loss rate of conductor. Based on the correlation function for the Reynolds numbers of the conductor and Al ball (i.e., (20)), the Reynolds number of the conductor $R e_{c}$ can be calculated. Then, the convective heat loss rate of conductor is also determined by the calculated $\operatorname{Re}_{\mathcal{C}}$ and (3)-(8).

(4) Calculation of $I_{a m p}$. Using the ambient temperature, global solar irradiance collected by the model device and the obtained convective heat loss rate of conductor in step (3), $I_{a m p}$ is calculated through (2).

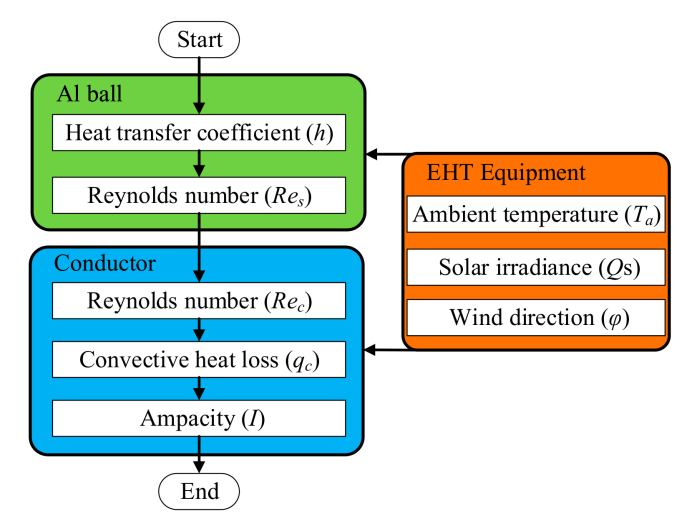

Figure 7. Calculation flowchart of conductor ampacity in EHT model.

\section{Validation of EHT Model Based on FEM}

In this section, a three-dimensional FEM of the Al ball in the model device is established by COMSOL to simulate the temperature rise characteristics of the $\mathrm{Al}$ ball with different wind speeds [40]. Based on the simulation results of temperature rise in the $\mathrm{Al}$ ball and the calculation process in Figure 7, the $I_{a m p}$ of the EHT model $I_{E H T}$ is obtained. Meanwhile, the $I_{a m p}$ of the IEEE standard $I_{I E E E}$ under the same conditions is also calculated. The EHT model is verified by comparing the results of $I_{E H T}$ and $I_{I E E E}$. Figure 8 shows the specific validation process for the EHT model. 


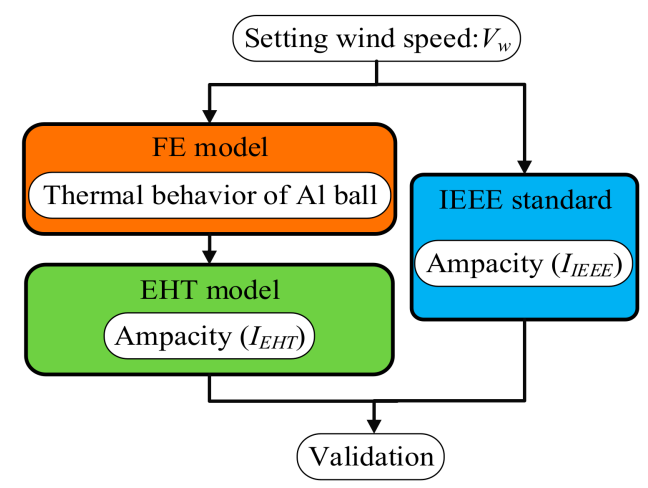

Figure 8. Validation process of EHT model.

\subsection{Setting and Results of FEM}

Before applying the EHT model proposed in this paper, a thermal-fluid coupling FE simulation model of the Al ball in the model device should be established to obtain the thermal behavior of the Al ball. The established geometric model is shown in Figure 9. The radius of the Al ball should not be set too large, otherwise an overlarge radial temperature difference will be caused. In the case of large radial temperature difference, the heat conduction inside the $\mathrm{Al}$ ball cannot be ignored. However, the heat conduction is not taken into account in the heat balance equation of the $\mathrm{Al}$ ball (i.e., (11)) in the EHT model. Therefore, the error is inevitably introduced in the calculation of the convective heat transfer coefficient $h$ (i.e., (21)) with an overlarge radius of the $\mathrm{Al}$ ball. In this paper, according to the above analysis, the radius of the $\mathrm{Al}$ ball is set to $1.25 \mathrm{~cm}$. In addition, a concentric sphere is also established as the air domain. To ensure the outer boundary temperature of the air domain is consistent with the ambient temperature, the radius of spherical air domain is set as $25 \mathrm{~cm} \mathrm{[41].}$ The ambient temperature is set to $25^{\circ} \mathrm{C}$. The internal heat source power $q_{g s}$ of (11) is $0.7 \mathrm{~W}$ to ensure that the steady-state temperature of the $\mathrm{Al}$ ball does not exceed $50^{\circ} \mathrm{C}$.

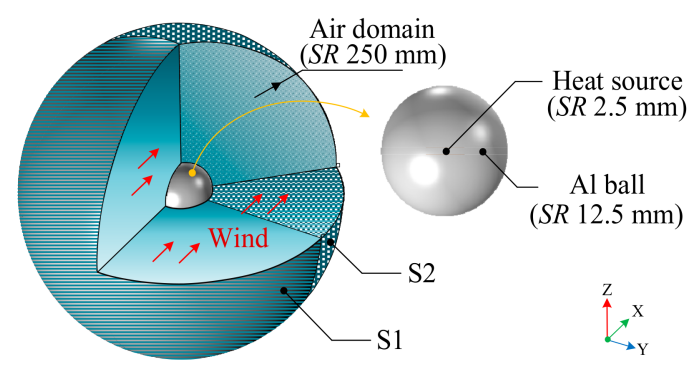

Figure 9. Geometry in FEM of Al ball.

As the global solar irradiance has little impact on $I_{a m p}$, the solar heat gain rate is not considered in the FE model. The boundary conditions of the thermal field contain the heat radiation and heat convection on the surface of $\mathrm{Al}$ ball. The simulation of heat radiation is achieved by setting the emissivity of the Al. In this section, the emissivity is set as 0.2 for calculation. The simulation of heat convection is realized by thermal-fluid coupling. For the boundary conditions of the fluid field, the boundary S1 of the air domain (as shown in Figure 9) is set as the air inlet, while the boundary S2 (as shown in Figure 9) is set as the air outlet. Then, the standard $k-\varepsilon$ model of the turbulence model is adopted to solve the fluid field. Because it cannot only guarantee the accuracy of the calculation results, but also avoid a long computation time [42]. Moreover, it is noted that the effect of air gravity is also considered during the solution of fluid field.

The transient calculation time is set to $80 \mathrm{~min}$, and the transient and steady temperature distribution results of the $\mathrm{Al}$ ball can be obtained. Figure 10 shows the steady-state simulation results with a wind 
speed of $1 \mathrm{~m} / \mathrm{s}$, including the temperature distribution of the Al ball and the wind speed distribution in the surrounding air domain. The results in Figure 10 indicate that, due to the blocking effect of the $\mathrm{Al}$ ball on the wind, the temperature on the leeward side of the $\mathrm{Al}$ ball is higher than that on the windward side. There is still a temperature difference of $3.1^{\circ} \mathrm{C}$ in the $\mathrm{Al}$ ball. In order to obtain a conservative $I_{a m p}$ result, the highest temperature on the leeward side is selected as the temperature of Al ball.

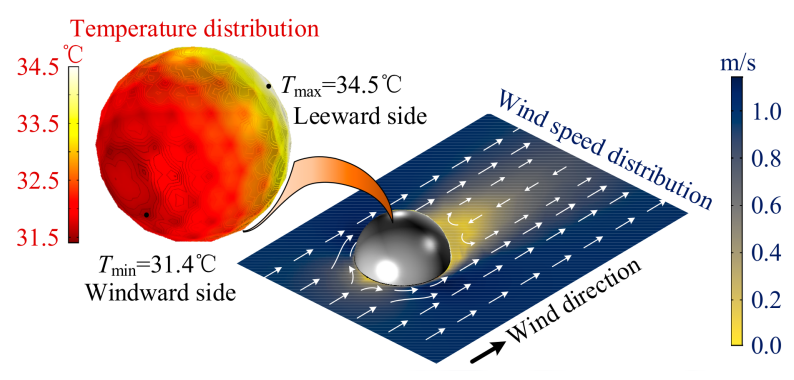

Figure 10. Steady-state calculation results of FE model with $V_{w}=1 \mathrm{~m} / \mathrm{s}$.

\subsection{Validation of EHT Model}

For the validation of the EHT model in this section, the wind direction is set to $90^{\circ}$, and an ACSR $240 / 30 \mathrm{~mm}^{2}$ overhead conductor is selected to calculate the $I_{a m p}$. Based on the output thermal behavior curve (including transient and steady state) of the FE model in Section 5.1, the $I_{a m p}$ results of the proposed EHT model $I_{E H T}$ at different wind speeds are calculated. Moreover, $I_{a m p}$ results of IEEE standard $I_{I E E E}$ are calculated under the same conditions. Figure 11 shows the results of $I_{E H T}$ and $I_{I E E E}$. In addition, the relative errors $\operatorname{err}_{I}$ of these two $I_{\text {amp }}$ results are also introduced, as shown by the red curves in Figure 11.

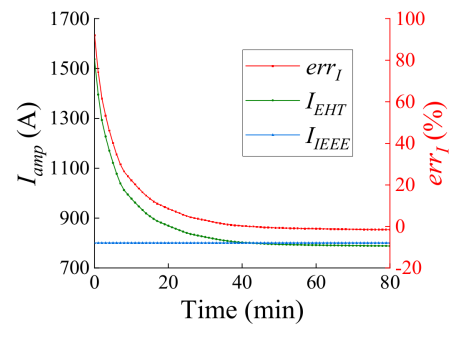

(a) $V_{w}=0.5 \mathrm{~m} / \mathrm{s}$

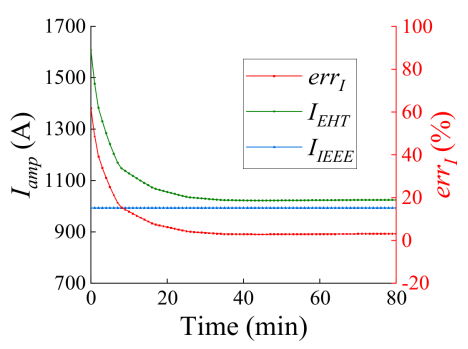

(c) $V_{w}=1.5 \mathrm{~m} / \mathrm{s}$

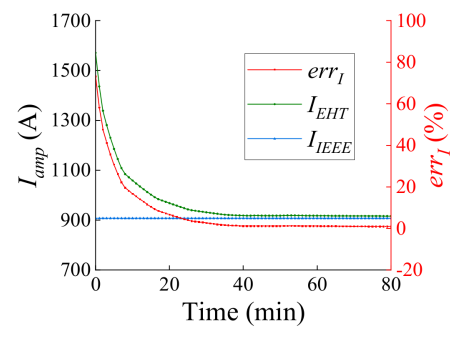

(b) $V_{w}=1 \mathrm{~m} / \mathrm{s}$

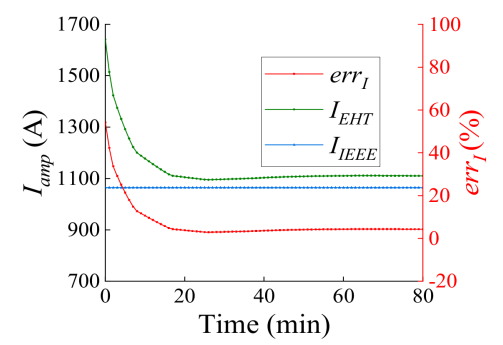

(d) $V_{w}=2 \mathrm{~m} / \mathrm{s}$

Figure 11. Comparison of conductor ampacity results from EHT model and IEEE standard.

According to the results in Figure 11, when the weather conditions remain constant, $I_{a m p}$ calculated by the IEEE standard $I_{I E E E}$ is a constant value, as shown by the blue curves in Figure 11 . However, $I_{\text {amp }}$ calculated by the EHT model $I_{E H T}$ is variable, as shown by the green curve in Figure 11 . Moreover, the $I_{E H T}$ results decrease and tend to be stable gradually with the increase in time. The error between $I_{I E E E}$ and $I_{E H T}$ also decreases gradually. When the $I_{E H T}$ results are stable, the error does not exceed $5 \%$. 
This phenomenon can be explained by analyzing the equivalent wind speed $V_{\text {w.calc }}$ calculated by the EHT model.

In the EHT model, the equivalent wind speed $V_{\text {w.calc }}$ can be calculated according to (15) and the calculated Reynolds number of the $\mathrm{Al}$ ball. Figure 12 shows the $V_{w \text { walc }}$ results corresponding to Figure 11 and the temperature rise results of the $\mathrm{Al}$ ball. It is indicated from Figure 12 that the $V_{w . c a l c}$ results decrease with the increase in time. When the $\mathrm{Al}$ ball temperature reaches steady-state, $V_{w . c a l c}$ is also stable and almost equal to the input wind speed $V_{w}$. The error between $V_{w . c a l c}$ and $V_{w}$ is mainly in the transient temperature rise of the $\mathrm{Al}$ ball. This is because in the initial phase of the transient state, the temperature difference between the $\mathrm{Al}$ ball and the environment is small. According to (21), although there is a differential term in the formula, the small denominator value results in a large calculated convective heat transfer coefficient $h$. This also causes the calculation results of $V_{w . c a l c}$ to increase in the initial phase of the transient state. As a result, according to Figures 11 and 12, the reason for the large error of $I_{E H T}$ in the initial phase is that the calculated $V_{w . c a l c}$ is much larger than the $V_{w}$.

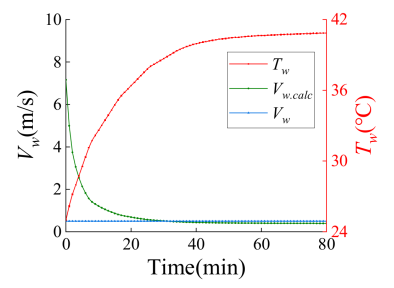

(a) $V_{w}=0.5 \mathrm{~m} / \mathrm{s}$

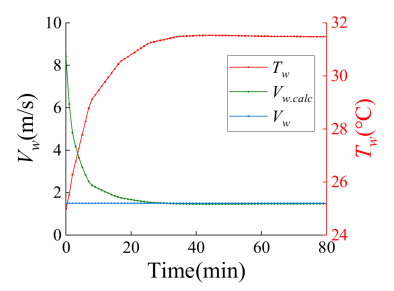

(c) $V_{w}=1.5 \mathrm{~m} / \mathrm{s}$

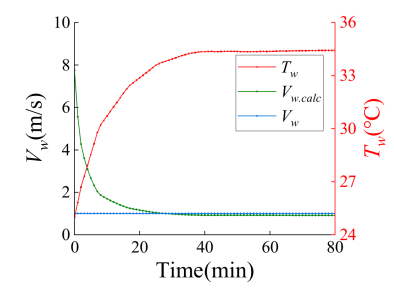

(b) $V_{w}=1 \mathrm{~m} / \mathrm{s}$

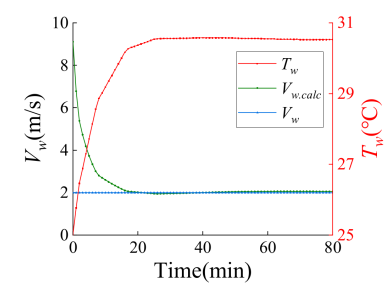

(d) $V_{w}=2 \mathrm{~m} / \mathrm{s}$

Figure 12. Comparison between the equivalent wind speeds calculated by EHT model and input wind speeds.

In order to more comprehensively verify the accuracy of the EHT model proposed in this paper, the calculation results of $I_{E H T}$ based on the Al ball steady-state thermal behavior and $I_{I E E E}$ at different wind speeds are obtained, as shown in Figure 13. In Figure 13, the results of $I_{E H T}$ and $I_{I E E E}$ both increase with the increase in wind speed. Compared with the $I_{I E E E}$ results, the relative errors of $I_{E H T}$ results are less than $6 \%$. Thus, the EHT model proposed in this paper can accurately evaluate $I_{a m p}$ in the case of using the steady-state thermal behavior of the Al ball.

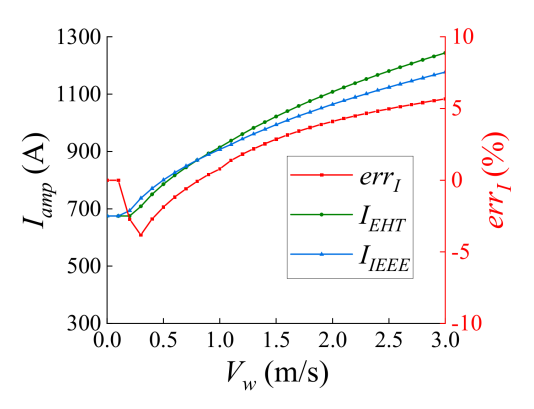

Figure 13. Comparison of conductor ampacity results from EHT model and IEEE standard under different wind speeds. 


\section{Conclusions}

The DTR technology can maximize the utilization for power transfer capacity of the existing overhead conductors. However, the existing models based on this technology have some deficiencies in measurement techniques related to wind speed. Therefore, in this paper an EHT model for DTR technology was proposed instead of wind speed measuring. In this model, the correlation of heat losses between the heating $\mathrm{Al}$ ball and conductor was established to calculate the conductor ampacity. Moreover, a thermal-fluid coupling FE model of the Al ball was established to simulate the implementation of the EHT model. Combined with the established FE model, the EHT model was validated by the IEEE standard. The results demonstrated that the EHT model showed a good agreement with the IEEE standard in the case of employing the steady thermal behavior of the Al ball. Since the EHT model can achieve desirable performance in evaluating the real-time ampacity of overhead conductors, it can facilitate a high utilization of overhead conductor, while also avoiding the restrictions of measuring technology related to wind speed.

The future work of this investigation will focus on the comparative analysis between the EHT model and the existing models based on experiments. In addition, the feasibility of using the transient thermal behavior of the $\mathrm{Al}$ ball to assess the conductor ampacity will be also explored.

Author Contributions: This paper is a result of the collaboration of all co-authors. D.G. and G.L. conceived and designed the study. Z.L. established the EHT model and wrote the paper. H.D. guided and revised the paper. R.P. and X.P. established the simulation model. R.W. provided statistical information. W.Z. refined the language. P.W. collected the references. All authors have read and agreed to the published version of the manuscript.

Funding: This research was funded by the Science and Technology Project of China Southern Power Grid, grant number GDKJXM20185588 and the National Natural Science Foundation of China, grant number No. 51977083.

Acknowledgments: The work described in this paper was supported by the Science and Technology Project of China Southern Power Grid (GDKJXM20185588) and the National Natural Science Foundation of China (No. 51977083).

Conflicts of Interest: The authors declare no conflict of interest.

\section{Nomenclature}

$\begin{array}{ll}\text { Variables } & \text { convective heat loss rate of conductor per unit length } \\ q_{c} & \text { radiative heat loss rate of conductor per unit length } \\ q_{r} & \text { solar heat gain rate of conductor per unit length } \\ q_{s} & \text { conductor current } \\ I & \text { conductor temperature } \\ T_{c} & \text { conductor resistance at the temperature of } T_{c} \\ R\left(T_{c}\right) & \text { maximum allowable temperature of conductor } \\ T_{c m a x} & \text { conductor ampacity } \\ I_{a m p} & q_{c} \text { in natural convection heat transfer } \\ q_{c n} & q_{c} \text { in forced convection heat transfer at low wind speeds } \\ q_{c 1} & q_{c} \text { in forced convection heat transfer at high wind speeds } \\ q_{c 2} & \text { air density } \\ \rho_{f} & \text { conductor diameter } \\ D_{0} & \text { ambient temperature } \\ T_{\mathrm{a}} & \text { thermal conductivity of air } \\ k_{f} & \text { wind direction factor } \\ K_{a n g l e} & \text { Reynolds number of conductors } \\ R_{c} & \text { angle between wind and axis of conductor } \\ \varphi_{c} & \text { wind speed } \\ V_{w} & \text { dynamic viscosity of air at the mean volume reference temperature } \\ \mu_{f} & \text { Steff-Boltzmann constant } \\ \sigma & \text { emissivity of the conductor surface } \\ \varepsilon & \text { solar absorptivity of the conductor surface } \\ \alpha & \text { global solar irradiance } \\ Q_{s} & \end{array}$




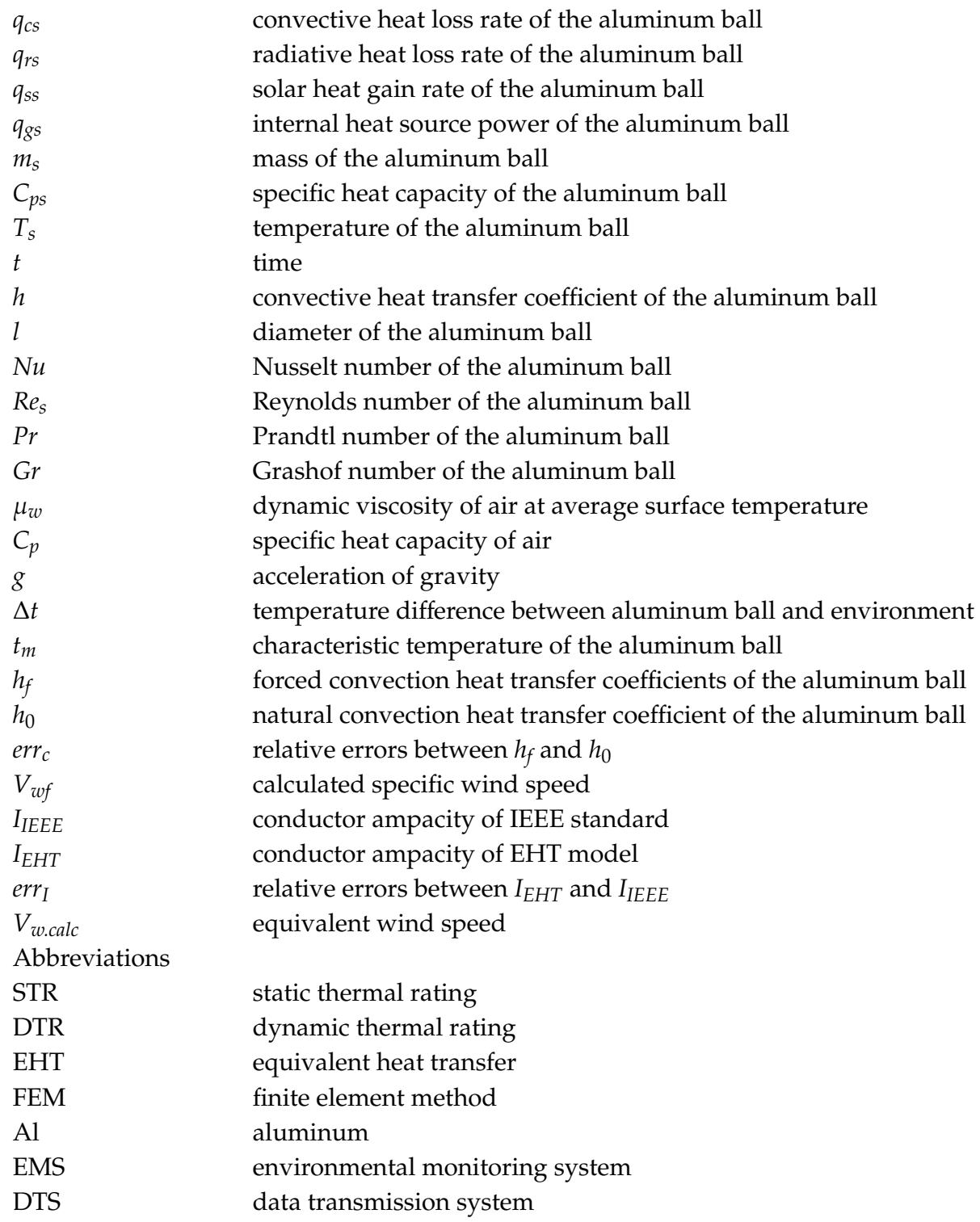

\section{References}

1. Mbuli, N.; Xezile, R.; Motsoeneng, L.; Ntuli, M.; Pretorius, J. A literature review on capacity uprate of transmission lines: 2008 to 2018. Electr. Power Syst. Res. 2019, 170, 215-221. [CrossRef]

2. Song, F.; Wang, Y.; Yan, H.; Zhou, X.; Niu, Z. Increasing the Utilization of Transmission Lines Capacity by Quasi-Dynamic Thermal Ratings. Energies 2019, 12, 792. [CrossRef]

3. Coletta, G.; Vaccaro, A.; Villacci, D. A review of the enabling methodologies for PMUs-based dynamic thermal rating of power transmission lines. Electr. Power Syst. Res. 2017, 152, 257-270. [CrossRef]

4. Lai, Q.; Chen, J.; Hu, L.; Cao, J.; Xie, Y.; Guo, D.; Liu, G.; Wang, P.; Zhu, N. Investigation of tail pipe breakdown incident for $110 \mathrm{kV}$ cable termination and proposal of fault prevention. Eng. Fail. Anal. 2020, 108, 104353. [CrossRef]

5. Uski, S. Estimation method for dynamic line rating potential and economic benefits. Int. J. Electr. Power Energy Syst. 2015, 65, 76-82. [CrossRef]

6. Liu, G.; Xu, Z.; Ma, H.; Hao, Y.; Wang, P.; Wu, W.; Xie, Y.; Guo, D. An improved analytical thermal rating method for cables installed in short-conduits. Int. J. Electr. Power Energy Syst. 2020, 123, 106223. [CrossRef]

7. Reddy, B.; Mitra, G. Investigations on High Temperature Low Sag (HTLS) Conductors. IEEE Trans. Power Deliv. 2020, 35, 1716-1724. 
8. Wan, H.; McCalley, J.; Vittal, V. Increasing thermal rating by risk analysis. IEEE Trans. Power Syst. 1999, 14, 815-821. [CrossRef]

9. Michiorri, A.; Nguyen, H.; Alessandrini, S.; Bremnes, J.B.; Dierer, S.; Ferrero, E.; Nygaard, B.; Pinson, P.; Thomaidis, N.; Uski, S. Forecasting for dynamic line rating. Renew. Sustain. Energy Rev. 2015, 52, 1713-1730. [CrossRef]

10. Teh, J.; Ooi, C.; Cheng, Y.; Zainuri, M.; Lai, C. Composite Reliability Evaluation of Load Demand Side Management and Dynamic Thermal Rating Systems. Energies 2018, 11, 466. [CrossRef]

11. Davis, M.W. A new thermal rating approach: The real time thermal Rating System for strategic overhead conductor transmission lines. I. General description and justification of the Real Thermal Rating System. IEEE Trans. Power Appar. Syst. 1977, 96, 803-809. [CrossRef]

12. Teh, J.; Lai, C.; Muhamad, N.; Ooi, C.; Cheng, Y.; Zainuri, M.; Ishak, M. Prospects of Using the Dynamic Thermal Rating System for Reliable Electrical Networks: A Review. IEEE Access 2018, 6, 26765-26778. [CrossRef]

13. Dupin, R.; Kariniotakis, G.; Michiorri, A. Overhead lines Dynamic Line rating based on probabilistic day-ahead forecasting and risk assessment. Int. J. Electr. Power Energy Syst. 2019, 110, 565-578. [CrossRef]

14. Douglass, D.A.; Edris, A.A. Real-time monitoring and dynamic thermal rating of power transmission circuits. IEEE Trans. Power Deliv. 1996, 11, 1407-1418. [CrossRef]

15. Jiang, J.; Liang, Y.; Chen, C.; Zheng, X.; Chuang, C.; Wang, C. On Dispatching Line Ampacities of Power Grids Using Weather-Based Conductor Temperature Forecasts. IEEE Trans. Smart Grid 2018, 9, 406-415. [CrossRef]

16. Jiang, J.; Wan, J.; Zheng, X.; Chen, C.; Lee, C.; Su, L.; Huang, W. A Novel Weather Information-Based Optimization Algorithm for Thermal Sensor Placement in Smart Grid. IEEE Trans. Smart Grid 2018, 9, 911-922. [CrossRef]

17. Michiorri, A.; Taylor, P.C.; Jupe, S.C.E.; Berry, C.J. Investigation into the influence of environmental conditions on power system ratings. Proc. Inst. Mech. Eng. Part A J. Power Energy 2009, 223, 743-757. [CrossRef]

18. CIGRE Working Group B2. Guide for Thermal Rating Calculations of Overhead Lines; Technical Brochure 601; CIGRE: Paris, France, 2014.

19. Foss, S.D.; Maraio, R.A. Dynamic line rating in the operating environment. IEEE Trans. Power Deliv. 1990, 5 , 1095-1105. [CrossRef]

20. Bose, A. Smart Transmission Grid Applications and Their Supporting Infrastructure. IEEE Trans. Smart Grid 2010, 1, 11-19. [CrossRef]

21. Zainuddin, N.; Abd Rahman, M.; Ab Kadir, M.; Ali, N.; Ali, Z.; Osman, M.; Mansor, M.; Ariffin, A.; Abd Rahman, M.; Nor, S.; et al. Review of Thermal Stress and Condition Monitoring Technologies for Overhead Transmission Lines: Issues and Challenges. IEEE Access 2020, 8, 120053-120081. [CrossRef]

22. Monseu, M. Determination of thermal line ratings from a probabilistic approach. In Proceedings of the Third International Conference on Probabilistic Methods Applied to Electric Power Systems (Conf. Proc. No.338), London, UK, 3-5 July 1991; pp. 180-184.

23. Zhao, Y.; Han, Z.; Xie, Y.; Fan, X.; Nie, Y.; Wang, P.; Liu, G.; Hao, Y.; Huang, J.; Zhu, W. Correlation Between Thermal Parameters and Morphology of Cross-Linked Polyethylene. IEEE Access 2020, 8, 19726-19736. [CrossRef]

24. Xie, Y.; Zhao, Y.; Bao, S.; Wang, P.; Huang, J.; Liu, G.; Hao, Y.; Li, L. Rejuvenation of Retired Power Cables by Heat Treatment: Experimental Simulation in Lab. IEEE Access 2020, 8, 5635-5643. [CrossRef]

25. Ghafourian, M.; Bridges, G.E.; Nezhad, A.Z.; Thomson, D.J. Wireless overhead line temperature sensor based on RF cavity resonance. Smart Mater. Struct. 2013, 22, 075010. [CrossRef]

26. Li, Q.; Zhou, Z.; Zhou, W.; Wei, J.; Wang, K.; Liu, G.; Deng, H.; Wang, P.; Shu, J. A case study on an explosion accident of a $110 \mathrm{kV}$ porcelain housed MOA. Eng. Fail. Anal. 2020, 115, 104665. [CrossRef]

27. Lecuna, R.; Castro, P.; Manana, M.; Laso, A.; Domingo, R.; Arroyo, A.; Martinez, R. Non-contact temperature measurement method for dynamic rating of overhead power lines. Electr. Power Syst. Res. 2020, 185, 106392. [CrossRef]

28. Olsen, R.; Edwards, K. A new method for real-time monitoring of high-voltage transmission-line conductor sag. IEEE Trans. Power Deliv. 2002, 17, 1142-1152. [CrossRef]

29. Seppa, T.O. Accurate ampacity determination: Temperature-sag model for operational real time ratings. IEEE Trans. Power Deliv. 1995, 10, 1460-1470. [CrossRef] 
30. Mahin, A.; Hossain, M.; Islam, S.; Munasinghe, K.; Jamalipour, A. Millimeter Wave Based Real-Time Sag Measurement and Monitoring System of Overhead Transmission Lines in a Smart Grid. IEEE Access 2020, 8, 100754-100767. [CrossRef]

31. Polevoy, A. Impact of Data Errors on Sag Calculation Accuracy for Overhead Transmission Line. IEEE Trans. Power Deliv. 2014, 29, 2040-2045. [CrossRef]

32. IEEE. IEEE Std 738-2012: IEEE Standard for Calculating the Current-Temperature Relationship of Bare Overhead Conductors; IEEE Standard Association: Washington, DC, USA, 2013.

33. Morgan, V.T. Rating of bare overhead conductors for continuous currents. Proc. Inst. Electr. Eng. 2010, 114, 1473-1482. [CrossRef]

34. CIGRE Working Group 22.12. The Thermal Behaviour of Overhead Conductors Section 1 and 2: Mathematical Model for Evaluation of Conductor Temperature in the Steady State and the Application Thereof. Electra 1992, 4, 107-125.

35. Whitaker, S. Forced convection heat transfer correlations for flow in pipes, past flat plates, single cylinders, single spheres, and for flow in packed beds and tube bundles. AICHE J. 1972, 18, 361-371. [CrossRef]

36. Taylor, C.S.; House, H.E. Emissivity and Its Effect on the Current-Carrying Capacity of Stranded Aluminum Conductors. Trans. Am. Inst. Electr. Eng. Part 3 1956, 75, 970-976.

37. Rigdon, W.S.; House, H.E.; Grosh, R.J.; Cottingham, W.B. Emissivity of Weathered Conductors after Service in Rural and Industrial Environments. Trans. Am. Inst. Electr. Eng. Part 3 1962, 81, 891-896. [CrossRef]

38. Daoush, W.; Swidan, A.; El-Aziz, G.A.; Abdelhalim, M. Fabrication, Microstructure, Thermal and Electrical Properties of Copper Heat Sink Composites. Mater. Sci. Appl. 2016, 7, 542-561. [CrossRef]

39. Weltner, K. Measurement of specific heat capacity of air. Am. J. Phys. 1993, 61, 661-662. [CrossRef]

40. Comsol Multiphysics. Heat Transfer Module User's Guide; Comsol AB Group: Stockholm, Sweden, 2006.

41. Zhang, T.; Zheng, W.; Xie, Y.; Yuan, J.; Xu, T.; Wang, P.; Liu, G.; Guo, D.; Zhang, G.; Liang, Y. A case study of rupture in $110 \mathrm{kV}$ overhead conductor repaired by full-tension splice. Eng. Fail. Anal. 2020, 108, 104349. [CrossRef]

42. Velusamy, K.; Sundararajan, T.; Seetharamu, K. Interaction effects between surface radiation and turbulent natural convection in square and rectangular enclosures. J. Heat Transf. Trans. ASME 2001, 123, 1062-1070. [CrossRef]

(C) 2020 by the authors. Licensee MDPI, Basel, Switzerland. This article is an open access article distributed under the terms and conditions of the Creative Commons Attribution (CC BY) license (http://creativecommons.org/licenses/by/4.0/). 